\title{
AS MULHERES NA MOBILIDADE ACADÊMICA INTERNACIONAL: UMA CARACTE RIZAÇÃO DAS PESQUISADORAS BRASILEIRAS NA UNIVERSIDADE DO MINHO
}

\author{
Sônia Cerqueira \& Rita Ribeiro
}

\begin{abstract}
RESUMO
A ciência tem avançado no debate sobre as relações de gênero, todavia ainda repousa sobre desníveis entre homens e mulheres, o que os conduz a escolhas e motivações distintas no âmbito da sua carreira acadêmica e científica. Com as exigências da internacionalização da educação, novos desafios se impõem para as mulheres, sobretudo, em relação à sua inserção no contexto das estratégias políticas adotadas para atender à dinâmica global da educação. Dentre estas estratégias, encontra-se a mobilidade acadêmica internacional, cujo objetivo é estimular o envio de estudantes e pesquisadores para centros de pesquisa no estrangeiro. O sistema brasileiro de Ciência e Tecnologia vem alargando investimentos neste setor, com a distribuição de bolsas de pesquisa para os diversos graus. Mas qual a representação feminina neste cenário e quais os significados que atribuem a esta prática da mobilidade? A partir de um inquérito realizado com 52 mulheres brasileiras em mobilidade acadêmica na Universidade do Minho, inscritas em cursos de pós-graduação, este estudo objetivou traçar um perfil destas estudantes e pesquisadoras, abordando as suas características pessoais, sociais, culturais e acadêmicas, além das principais motivações subjetivas que definem a escolha por este tipo de mobilidade.
\end{abstract}

\section{Palavras-chave}

Mulheres e ciência; mobilidade acadêmica; pesquisadoras brasileiras; Universidade do Minho

\section{INTRODUÇÃo}

O artigo em questão é um recorte de uma pesquisa pós-doutoral sobre mobilidade acadêmica cujo foco é uma abordagem preliminar acerca das mulheres brasileiras em mobilidade acadêmica em cursos de pós-gradução da Universidade do Minho (UMinho), inscritas entre os anos de 2013 e 2014. É relevante esclarecer que o intuito deste trabalho é apresentar uma caracterização geral do perfil do grupo pesquisado, contemplando aspectos pessoais, sociais, culturais, acadêmicos e profissionais. Procura-se também conhecer as motivações subjetivas que interferem na escolha pelo intercâmbio internacional, de modo a identificar possíveis particularidades e significados que orientam esta conduta de mobilidade das cientistas investigadas. O interesse, portanto, não é o de avaliar a relação de gênero no contexto da mobilidade, mas de apenas destacar algumas reflexões sobre o perfil de mulheres pesquisadoras brasileiras que se encontram em mobilidade acadêmica na Universidade do Minho. Todavia, considerando que a relação de gênero entrecruza, de alguma forma, o debate sobre o avanço das mulheres no sistema de Ciência e Tecnologia (C\&T) e no âmbito acadêmico, esta será tratada, ainda que perifericamente. 
À luz destes objetivos, o artigo está estruturado em duas partes: a primeira, aborda a inserção da mulher no sistema C\&T e no processo de mobilidade acadêmica; e, a segunda, centra-se na análise dos dados empíricos coletados, versando sobre a caracterização geral das mulheres brasileiras em mobilidade na UMinho e sobre o tipo particular de mobilidade daí decorrente.

\section{Algumas Reflexões SObre A MUlher na CiÊnCia}

Antes de discutir a inserção das mulheres nos processos de mobilidade acadêmica, há que pontuar algumas questões que acompanham a sua trajetória na academia e na vida profissional, entendendo como ocorre o seu acesso à ciência e à mobilidade acadêmica. Inevitavelmente, ainda que o debate sobre gênero não seja o foco deste trabalho, o mesmo será levantado, já que se torna impossível compreender a participação feminina na ciência e nas suas instituições sem recorrer às relações de disputa e poder que explicam o campo científico.

No caso brasileiro, os indicadores de C\&T apontam para a crescente participação das mulheres nas atividades científicas. Todavia, esta atuação feminina ainda é limitada, sobretudo na ocupação de cargos de direção e no acesso a certos cursos considerados masculinos (Saboya, 2013). A escolha de carreiras típicas de gênero provoca uma situação de desequilíbrio nas oportunidades e projeções profissionais futuras entre homens e mulheres, gerando formas de segregação que conduzem as mulheres para profissões consideradas femininas, geralmente menos valorizadas no mercado de trabalho. Aliado a este tipo de segregação (horizontal), há um outro mecanismo social, de segregação vertical, que tende a manter as mulheres em posições mais subordinadas, impedindo-as de progredirem em suas carreiras (Olinto, 2011). Estas diferenças fazem diminuir as oportunidades das mulheres ocuparem certas posições na hierarquia profissional, nomeadamente nos lugares e cargos de destaque nas atividades científicas.

Tal realidade, de um modo geral, mostra como a divisão sexual continua a demarcar espaços na ciência e na educação, contribuindo para a segregação das mulheres no ensino superior e na carreira científica, conforme sugere o conceito de "teto de vidro" (Williams, 1995). Este conceito representa, na verdade, uma espécie de barreira invisível que impossibilita a progressão acadêmica e o crescimento das mulheres no mercado de trabalho. Entretanto, no caso dos homens, a autora afirma que há um movimento contrário ao "teto de vidro": seria um movimento que empurra os homens para cima, criando circunstâncias de privilégio que os lançam para a ocupação de cargos de maior prestígio e salário. Para descrever esta situação, Williams (1995) designou a expressão "escada rolante de vidro". O problema reside no fato de que, mesmo sendo capazes, eficientes e qualificadas, as mulheres acabarem sendo destinadas a ocupar cargos subordinados aos homens, tornando-se difícil a possibilidade de ascensão na carreira.

Entender os níveis de desigualdade de gênero na ciência é importante para avaliar a falta de oportunidade das mulheres na própria produção do conhecimento e no acesso ao mercado de trabalho. Adotar políticas públicas direcionadas para a qualificação 
profissional das mulheres, de modo a inseri-las no campo de batalha do mercado, com as mesmas oportunidades de competitividade dos homens, é uma forma de lhes garantir direitos e de possibilitar a sua progressão na carreira. Mas de que forma o sistema de ciência e tecnologia brasileiro vem absorvendo a participação feminina nesta realidade?

O Censo de 2010 do Instituto Brasileiro de Geografia e Estatística (IBGE) contabilizou 190.755.799 habitantes no Brasil. Dentre estes, 51\% são mulheres e 49\% são homens. Os dados mostraram ainda que elas estudam mais e estão mais presentes no mercado de trabalho, no entanto, têm formação e ocupam cargos que conferem menores salários. O número de mulheres responsáveis pelas famílias e domicílios cresceu, sendo que do total de 50 milhões de famílias residentes em domicílios particulares em 2010, o sexo feminino era responsável por $37,3 \%$. Considerando as famílias compostas por responsável sem cônjuge e com filho(s), as mulheres perfazem a maioria, com um total de $87,4 \%$. Ademais, entre elas, há significativas diferenças regionais e de cor, o que fortalece as desigualdades de gênero e aumenta as vulnerabilidades das mulheres brasileiras (IBGE, 2015).

Alargando este quadro para a inserção feminina na educação, o Censo de 2010 identificou que o nível de instrução das mulheres continuou mais elevado que o dos homens, sendo que as mulheres constituem a maioria entre os universitários e entre os doutores. Embora no Brasil elas sejam menos numerosas entre os professores universitários e ocupem menos espaços de direção, prestígio e poder na academia e na ciência, é possível perceber uma maior abertura à entrada de mulheres no sistema C\&T. Há a considerar também que a institucionalização da ciência brasileira faz parte da história recente do país e isto repercute-se na inserção tardia da presença feminina na comunidade científica:

Até o século $X X$, o número de instituições voltadas para a ciência era muito limitado e foi no final dos anos de 1960, com a edição do Plano Estratégico de Desenvolvimento Nacional, que a questão científica e tecnológica surgiu como presença constante no planejamento nacional. Apesar da recente institucionalização da ciência brasileira, foi também nos anos de 1980 e 1990 que as mulheres brasileiras aumentaram sua participação no setor. (Leta, 2003, p. 274)

Dessa forma, à medida que avançaram as instituições de fomento à pesquisa também se verificou um aumento do sexo feminino no campo científico e acadêmico. Agências financiadoras de pesquisa do governo federal, como CNPq (Conselho Nacional de Desenvolvimento Científico e Tecnológico) e CAPES (Coordenação de Aperfeiçoamento de Pessoal de Nível Superior), hoje desempenham um importante papel para a formação de capital humano no país, cujos registros apontam para uma tendência crescente no número de bolsas destinadas a mulheres pesquisadoras.

Por outro lado, e embora seja visível o processo de feminização no acesso a diferentes modalidades de bolsas de pesquisa, verificando-se uma maior entrada de mulheres no sistema C\&T do Brasil, constata-se também que há uma diminuição de bolsistas 
do sexo feminino para as bolsas com um maior nível hierárquico. As dificuldades de acesso a estas bolsas de maior destaque e reconhecimento nos campos científico e acadêmico, como as bolsas de produtividade, ao que tudo indica, são um fator que marca a fragilidade do crescimento profissional dessas mulheres. Assim:

Esse é um indicativo de que uma parcela das mulheres que passam pelos primeiros estágios de capacitação e treinamento para as atividades científicas, se "perdem" ao longo desse caminho ou simplesmente não ganham o reconhecimento dos pares através da concessão de suas bolsas. (Leta, 2003, p. 276-277)

Segundo a autora, talvez isso possa confirmar que existe algum tipo de discriminação de gênero no sistema de concessão de bolsas, sobretudo para os casos de bolsas de produtividade que obedecem a critérios de excelência. Dados recentes do CNPq revelam que a participação feminina nas bolsas de produtividade em pesquisa equivale a $36 \%$ do total de bolsas concedidas em 2013, cujo rácio é de 4.970 bolsistas mulheres para 8.994 bolsistas homens. Portanto, a sub-representação do sexo feminino é uma realidade que ainda acompanha a ciência brasileira, e, em boa medida, os países economicamente desenvolvidos. Embora os dados variem nas particularidades de cada país, um elemento comum é o fato de, em geral, as mulheres continuarem a ter um espaço reduzido em postos de liderança e em altos cargos do sistema C\&T.

No entender de Leta e Martins (2008), com efeito, também há uma desigual distribuição por sexo no Brasil para as atividades docentes e de orientação acadêmica, contribuindo, assim, para um menor índice de experiência com pesquisa e com publicações. Para as mulheres cientistas isto tem como consequência um desigual acúmulo de capital científico, se comparado com os homens, o que trará implicações sérias para a sua progressão na carreira. Aliada a esta realidade, reside o fato de culturalmente as mulheres serem destinadas a ter um envolvimento maior com a família, sendo chamadas a responder mais pela organização da casa e pelos cuidados com os filhos, algo que interfere diretamente na sua vida profissional. Na verdade, o cenário brasileiro aqui descrito encarna em boa medida os desafios encontrados pelas mulheres mesmo nos países desenvolvidos, onde existem universidades e centros de pesquisa já bem consolidados. E isso vale também para entender todas as instâncias e atividades que caracterizam os percursos das mulheres no trabalho científico, como é o caso da mobilidade internacional.

$\mathrm{Na}$ verdade, a própria sub-representação das mulheres nas áreas das ciências exatas e das engenharias já comprova a força da divisão por gênero que prevalece no Brasil, assente no desenvolvimento de habilidades e gostos definidos por sexo. Tal divisão sexual também se repercute nas trajetórias de mobilidade, pois geralmente os países receptores mais procurados são os que representam referências de excelência nas áreas das engenharias, tecnologias e matemática, justamente nas áreas onde ainda persistem dificuldades de acesso do sexo feminino. Disso decorre a necessidade de compreender quem são as mulheres inseridas na mobilidade internacional e o que procuram nestas trajetórias móveis, quais são as suas principais motivações na escolha da universidade 
e do país de acolhimento e quais os significados e sentidos de mobilidade que vêm ajudando a construir nas suas práticas.

Um projeto de investigação internacional sobre mobilidade (MOBEX), citado por Delicado e Alves (2013), que conta no seu conjunto com algumas análises centradas no gênero como variável importante, revela que:

[...] a sub-representação das mulheres na ciência conduz à sub-representação destas na mobilidade, evidenciando ainda que as mulheres são afetadas por constrangimentos específicos no respeitante à mobilidade (família e filhos). Uma menor mobilidade implicará, por sua vez, uma progressão mais lenta na carreira, um menor número de oportunidades para o exercício de cargos de coordenação e direção ("teto de vidro") ou até o abandono da ciência (uma das causas da "fuga na canalização"). (Delicado \& Alves, 2013, p. 10)

Para as mulheres cientistas, por exemplo, o deslocamento geográfico por um longo período de tempo geralmente comporta mais dificuldades no âmbito familiar do que ocorre com os homens. Se considerarmos a mobilidade como exigência da internacionalização da educação e, portanto, como requisito para a qualificação profissional, a participação em programas de mobilidade pode ser uma grande oportunidade perdida para uma progressão mais efetiva na carreira de mulheres. A própria ciência e as suas instituições, ainda centradas numa perspectiva androcêntrica do mundo, por vezes não promovem as condições favoráveis para o intercâmbio internacional das mulheres, conduzindo-as ou para um estado de estagnação na profissão, ou para o total abandono da sua carreira científica.

Esta realidade de exclusão pode se manifestar de diversas formas. Num estudo realizado com acadêmicas latino-americanas em mobilidade científica em Portugal, França e Padilha (2013) observaram como os mecanismos sexistas e racistas estão presentes nesta experiência internacional:

O caso de investigadoras do Sul em mobilidade científica em centros do Norte resulta em uma dinâmica social na qual as assimetrias geopolíticas somam-se à intersecção dos marcadores de raça, etnia e gênero contribuindo diretamente para a materialização de situações excludentes e opressoras que afetam não apenas a experiência pessoal desses sujeitos, mas também a legitimação e o reconhecimento de sua produção acadêmica. (França \& Padilha, 2013, p. 02)

Com efeito, estas questões interferem no desenvolvimento das suas trajetórias e no seu reconhecimento profissional. É claro que, conforme já dito antes, as mulheres hoje ocupam nas suas profissões, espaços frequentemente conquistados em decorrência da sua luta por direitos legítimos, mas também porque passaram a ser úteis numa economia capitalista orientada para a produtividade e a competitividade. O que resta compreender melhor é como a identidade feminina vem se constituindo neste contexto, como as mulheres pesquisadoras vêm atribuindo significados subjetivos às suas escoIhas, e neste caso, às suas escolhas de mobilidade acadêmica. 
Considerando os novos desafios do mundo globalizado, o sistema científico e tecnológico brasileiro tem apostado na internacionalização do conhecimento, a fim de cumprir com vigor as estratégias políticas e econômicas dos países centrais. No quadro destas estratégias, assentes na competitividade e na produtividade, compete aos envolvidos nos meios acadêmico e científico aumentar o número de publicações internacionais e criar redes internacionais de colaboração e investigação. Dessa forma, as carreiras científicas, com suas trajetórias individuais de progressão, se desenvolvem sob o pressuposto da mobilidade como princípio de obtenção de conhecimento e qualificação científica, e por isso avançam as políticas e os programas de incentivo ao intercâmbio. Neste contexto, os circuitos de mobilidade internacionalmente percorridos obedecem, em sua maioria, à lógica da periferia em direção aos grandes centros de ciência e tecnologia, embora a mobilidade também aconteça de forma multidirecional. De fato, de acordo com dados mundiais, $62 \%$ dos estudantes estrangeiros no mundo advêm de países "do sul" (países em desenvolvimento) e se dirigem a países "do norte" (em geral desenvolvidos), ao passo que $30 \%$ da mobilidade estudantil ocorre entre norte-norte e apenas 8\% entre sul-sul (Nogueira, Aguiar \& Ramos, 2008, p. 362). De acordo com o Compendio Mundial de la Educación 2010, os Estados Unidos aparecem como o principal destino da mobilidade internacional. (Castro \& Neto, 2012). O Brasil, portanto, não foge a esta regra, elegendo como primeiro país receptor os Estados Unidos, em segundo, a França, e em terceiro, Portugal.

As mulheres acabam sendo menos propensas do que os homens ao intercâmbio internacional, geralmente em decorrência de questões familiares (Ackers, 2004). Neste sentido, é comum ter mais mulheres investigadoras solteiras em mobilidade internacional do que homens, uma vez que nesta condição possivelmente conseguem ter uma dedicação maior ao trabalho científico. Da mesma forma, em situação de mobilidade, elas apresentam uma probabilidade menor em ter filhos do que o sexo masculino, inclusive por vezes tendo que tomar decisões difíceis a respeito das suas escolhas reprodutivas, ou abandonando a ciência para ter filhos, ou adiando a maternidade. E ainda, no âmbito da mobilidade, tendem mais a protelar a sua própria carreira em função da progressão profissional do parceiro (Ackers, 2001). Acabam, por questões culturais, mais propensas a permanecer ligadas a laços familiares mesmo em momentos de mobilidade, como é o caso das investigadoras que, em geral, diferentemente dos homens, costumam residir mais no estrangeiro com o companheiro e/ou filho(s) (Delicado, 2013). Estes dados confirmam que as condições familiares têm grande importância nas decisões femininas no que se refere às suas carreiras acadêmicas, o que podemos entender como resultado das relações de gênero construídas historicamente.

O debate sobre a dinâmica da imigração qualificada, sobretudo em relação à categoria específica da mobilidade internacional de mulheres investigadoras, é ainda pouco discutido, sendo, todavia, bastante necessário. Considerando que a mobilidade de estudantes e cientistas é parte indissociável da carreira acadêmica, faz-se relevante tomar como categoria de análise as experiências femininas em mobilidade no contexto acadêmico e científico, seja para desconstruir os estereótipos, seja para dar visibilidade às 
diferentes formas da mulher se inserir e atuar neste campo, construindo e reconstruindo significados e ações que contribuam para a sua trajetória profissional.

\section{MULHERES BRASILEIRAS EM MOBILIDADE NA UMINHO}

Os dados empíricos do estudo que aqui se apresenta foram recolhidos a partir da aplicação de questionário online, nos meses de Novembro e Dezembro de 2014 e Janeiro de 2015, encaminhado aos Centros de Investigação e a outros endereços eletrônicos relevantes da Universidade do Minho. O formulário utilizado foi o da ferramenta Google Docs e o programa para o tratamento dos dados foi o SPSS. No total, obteve-se 52 questionários respondidos por mulheres brasileiras pesquisadoras na UMinho. Visando estabelecer uma caracterização geral das respondentes, foram identificados aspectos diversos, tais como idade, naturalidade, sexo, estado civil, renda familiar, universidade brasileira com a qual manteve ou mantém vínculo acadêmico ou profissional e também os respectivos cursos, além das condições de morada no Brasil, de trabalho e de renda. Tentando entender como se constituiu a formação educacional das respondentes, foram feitas algumas perguntas acerca da sua bagagem social e cultural, não somente a partir da sua formação no ensino fundamental e médio, e na graduação e pós-graduação, mas também a partir do desenvolvimento de habilidades e conhecimentos que não necessariamente são adquiridos em sala de aula, mas que contribuem significativamente para a trajetória acadêmica. Da mesma forma, também se buscou conhecer a formação escolar tanto da mãe quanto do pai das brasileiras aqui pesquisadas. O estudo compreendeu ainda a mobilidade acadêmica a partir de aspectos relativos ao curso realizado na UMinho, a área de investigação, ano de início e previsão de conclusão, mas também procurou identificar as motivações para a escolha da instituição e também de Portugal, os gastos com despesas para assegurar a mobilidade e a disponibilidade de auxilio de agência de fomento à pesquisa. Considerando a integração acadêmica como aspecto crucial para a realização plena da mobilidade, o estudo visou identificar aspectos da relação do estudante com a UMinho, nas instâncias administrativa, acadêmica ou de pesquisa. Também foram levantados dados a respeito da integração social e cultural dentro e fora da universidade por parte das respondentes, sob a perspectiva de que é ponto relevante para se entender melhor a trajetória de mobilidade destas pesquisadoras brasileiras. Por fim, o inquérito também levantou questões relativas à avaliação que empreendem sobre a instituição escolhida e sobre a mobilidade em geral. Foram avaliados a estrutura física, o corpo administrativo, os docentes, os orientadores e os centros de pesquisa aos quais estão ou estiveram vinculadas na UMinho. Além disso, procurou-se compreender também como elas avaliam a sua produção acadêmica ao longo da mobilidade e a sua integração social e cultural e como avaliam as suas principais dificuldades enfrentadas na mobilidade.

Com caráter exploratório, o presente estudo contou com a análise de 52 casos de mulheres brasileiras em situação de mobilidade na Universidade do Minho. Dentre estes casos, o trabalho revelou que o percentual de respondentes com idade entre 20 a 30 anos é de $25 \%$, entre 31 a 40 anos é de $35 \%$, e acima de 40 até 50 anos é de $17 \%$, e acima 
de 50 anos é de $23 \%$. Considerando a naturalidade das respondentes e o agrupamento dos estados por região da federação brasileira, observou-se que o Sudeste abriga o maior percentual de casos (36\%), seguido pelo Nordeste (29\%). O percentual de respondentes naturais da região Sul $(23 \%)$ é praticamente o dobro da soma daqueles observados nas regiões Norte e Centro-Oeste (12\%) do país. A maior parte é jovem e solteira, e $21 \%$ têm filhos e, dentre estas que são mães, a maioria (73\%) tem mais de 40 anos. De todas as inquiridas, a maior parte possui rendimentos entre 3 a 6 mil reais por mês. É relevante atentar que não há mulheres com rendimentos superiores a 10 mil reais. Os dados também indicaram que um percentual significativo de mulheres (19\%) tem renda familiar abaixo de 5 salários mínimos (salário mínimo brasileiro: 788 reais), e pouco menos da metade (48\%) tem bolsa de estudo, sendo que, entre estas, $44 \%$ consideram a bolsa insuficiente para manter todas as suas despesas. Entre as bolsistas, $76 \%$ não têm filhos e a maioria destas está na faixa etária entre 30 a 40 anos. As mais jovens e sem filhos têm apoio financeiro de instituição de fomento à pesquisa para o desenvolvimento dos seus estudos, o que não ocorre entre as investigadoras com idade mais elevada.

A maioria das respondentes (58\%) mantém vínculo profissional com instituições de Ensino Superior no Brasil e é proveniente de escolas públicas brasileiras, tendo também concluído a sua graduação em universidades públicas. Sobre o nível de escolaridade dos pais, entre as respondentes o maior percentual correspondeu a pais e mães com nível superior completo. $71 \%$ afirmou ter pouca habilidade em falar o idioma inglês e somente $12 \%$ declarou falá-lo fluentemente. Quanto à quantidade de livros lidos por ano, o maior percentual (31\%) concentrou entre 5 a 8 livros. 23\% (o maior percentual) informaram que tem apenas uma publicação científica por ano. Entre as inquiridas que publicam, todas já o fizeram em âmbito internacional. $79 \%$ delas já tinham viajado para fora do país, mas somente $29 \%$ chegaram a fazer algum tipo de intercâmbio antes. A maioria ( $52 \%$ ) está fazendo Doutorado Integral na Universidade do Minho, o que pode, dentre outros fatores, ser explicado pela grande concorrência que vem acompanhando estes cursos no Brasil. Boa parte mantém vínculo na UMinho com cursos na área de Ciências Humanas e Ciências Sociais.

Entre as principais motivações na escolha por Portugal, aparecem, por ordem, o fato de ter o idioma português como língua oficial (81\%), a reputação da universidade escoIhida (58\%) e o custo de vida reduzido (56\%). Neste caso, o idioma de fato é um facilitador para o processo de integração social, porque pressupõe uma aproximação e familiaridade cultural com o país de origem, bem como uma alternativa de acesso à mobilidade internacional para os brasileiros que não dominam a língua inglesa. De qualquer forma, a exigência de proficiência em língua estrangeira é recorrente na ciência e na educação, seja no âmbito das universidades e centros de pesquisa internacionais, seja no nível nacional. A este respeito, Kaplan (2001, p. 12) elucida acerca do papel central da língua inglesa no sistema científico internacional:

Não só o inglês é o idioma indiscutível da ciência, mas, dada a importância do computador na internacionalização do inglês, os países de língua inglesa podem constituir um cartel virtual da informação científica, porque 
os sistemas de informação internacionais são organizados de acordo com uma sociologia do conhecimento baseada no inglês.

A preponderância da língua inglesa no sistema de C\&T é bastante significativa, principalmente porque também cresce o investimento em mobilidade para os países de língua inglesa. O Programa Brasileiro de Mobilidade Científica, por exemplo, é atualmente um dos principais meios de enviar estudantes e pesquisadores brasileiros para o exterior, nomeadamente para as universidades norte-americanas, onde se observam avanço tecnológico e inovação, suporte financeiro para a pesquisa e reputação do sistema científico. Portugal, portanto, estaria fora desse circuito dos grandes centros hegemônicos de excelência, embora comporte instituições renomadas. Neste sentido, o idioma português não contribui para classificar Portugal como um país atrativo para o novo modelo de internacionalização da educação em curso, especialmente marcado pelo domínio do inglês como idioma universal. Todavia, observa-se que, para o grupo pesquisado, o idioma português é de extrema importância, porque funciona como um mecanismo de integração, tanto no meio acadêmico, quanto no contexto das interações sociais extra-academia. Podemos colocar também a possibilidade de a mobilidade para Portugal, como país semi-periférico (Videira, 2013), procurar conciliar as necessidades de integração e socialização com as exigências da comunicação científica em língua inglesa, uma vez que também neste país são determinantes as exigências de proficiência no inglês no contexto da produção científica.

Em relação às motivações na escolha pela UMinho, as inquiridas afirmaram que o fizeram para melhorar o currículo acadêmico (77\%), desejo de mudança pessoal (55\%), desenvolver competências relacionadas à profissão (54\%) e conhecer outro país e sua cultura (48\%). É possível afirmar que a escolha por Portugal e pela Universidade do Minho resume dois sentimentos em relação à mobilidade: um de desejo de acolhimento e integração social e outro de busca por prestígio e reconhecimento acadêmico e científico. A Universidade do Minho responde a esta possibilidade de inserção na internacionalização da educação, o que significa dizer que para o grupo pesquisado esta mobilidade também representa um modelo competitivo de educação capaz de projetar retornos positivos para as suas carreiras.

Quanto à integração acadêmica, a pesquisa revelou que a maioria (67\%) das respondentes recebeu apoio acadêmico da UMinho, $37 \%$ efetuaram matrículas em unidades da universidade, $43 \%$ receberam convite para participar de aula inaugural e $42 \%$ receberam o ato normativo da instituição. Dentre as respondentes, a maioria (87\%) frequentou disciplinas na UMinho, $37 \%$ participou de grupos de pesquisa e $35 \%$ já publicou textos acadêmicos com seus orientadores desta universidade. Constatou-se que é praticamente a mesma proporção para as respondentes que moram sozinhas (36\%) em Portugal e para as que moram com companheiros e/ou filhos (35\%). Elas conseguem, em sua maioria, manter amizade com portugueses dentro e fora do ambiente acadêmico. $23 \%$ das respondentes se envolveram em relacionamentos amorosos com portugueses fora do ambiente acadêmico e menos ainda $(7,7 \%)$ se envolveram com colegas da UMinho. 
Acrescenta-se a isso, que as respondentes revelaram se relacionar principalmente com os seus compatriotas, o que, por um lado, pode ser reflexo de qualquer situação de mobilidade, mas, por outro, pode estar associado ao estigma que, embora em declínio, ainda existe em Portugal acerca das mulheres brasileiras, provocando problemas de integração social. A maioria (96\%) das respondentes, assim como acontecia no Brasil, frequenta atividades e espaços culturais em Portugal, tais como museus, cinemas, entre outros.

Em linhas gerais, as respondentes avaliam o intercâmbio de forma positiva, seja em relação à estrutura física, ao corpo administrativo, aos docentes, aos orientadores e aos centros de pesquisa, sendo o item "Orientador" o que obteve o maior percentual de avaliação "Excelente". Nota-se, contudo, que apesar do expressivo percentual de avaliações positivas da integração social e cultural e do intercâmbio em geral, as respondentes não deixam ou não deixaram de enfrentar dificuldades significativas durante a mobilidade. As mais expressivas, correspondendo aos maiores percentuais das respostas, dizem respeito à socialização (50\%), aos problemas econômicos (29\%), ao transporte (23\%), à cultura (21\%), à moradia (21\%), aos entraves administrativos (19\%) e acadêmicos (15\%), à alimentação (10\%) e aos fatores climáticos (4\%).

\section{CONSIDERAÇões FINAIS}

Este estudo indica, ainda que preliminarmente, alguns indícios em relação ao tipo particular de mobilidade em análise, seja pela escolha do país de destino, com todas as suas implicações, seja pelo próprio grupo investigado, mulheres brasileiras pesquisadoras em deslocamento acadêmico internacional. Quanto às formas hegemônicas de mobilidade acadêmica, Portugal se apresenta como um dos destinos semi-periféricos de mobilidade, visto que as suas universidades não estão entre as principais eleitas pelo sistema C\&T a nível global. Deste modo, podemos sugerir que este país foge do padrão competitivo esperado nos grandes centros de pesquisa, para onde se dirigem os holofotes em busca dos "cérebros brilhantes", e para onde se dirigem também os maiores investimentos para a mobilidade internacional, especialmente nas áreas das ciências exatas e tecnologias. Ademais, a importância crescente do inglês como idioma universal da ciência é legitimado nestes grandes centros de pesquisa, e progressivamente perpetuado nos centros periféricos. A outra particularidade refere-se ao grupo pesquisado, que comporta singularidades na sua condição de gênero, o que se reflete nas suas opções de mobilidade, bastante centradas em motivações que podemos designar de caráter social. Isto sugere que há uma relação entre gênero, área de pesquisa e países de destino da mobilidade. Todavia, aqui neste estudo exploratório não é possível confirmar tal relação, sendo necessário ampliar e aprofundar estas questões posteriormente.

Os sentidos subjetivos que circunscrevem as práticas de mobilidade têm muito a revelar como as mulheres conduzem a sua carreira e como absorvem as exigências objetivas do mercado e da sua profissão. Competitividade e produtividade são elementos que explicam a nova dinâmica educacional, voltada para a internacionalização do ensino e para o estímulo à mobilidade acadêmica. Nestes termos, a experiência de mobilidade 
internacional aumenta as oportunidades de se ter um currículo competitivo. Todavia, as chances se multiplicam quando tal mobilidade se direciona para os grandes centros de investigação, lugares caracterizados por grandes disputas de nível acadêmico e científico, como é o caso dos Estados Unidos, que é hoje o primeiro destino escolhido pelos restantes países para a realização de mobilidade académica.

O novo cenário educacional, globalizado e competitivo, põe em evidência as relações de poder que deflagram no sistema C\&T como um todo, seja no que se refere às relações entre os países e aos seus modelos de educação e de mercado, seja ao nível das relações étnicas, etárias e de gênero. Sem descartar as estruturas de dominação e de poder inscritas na ciência e na academia, e sem abraçar conclusões, este trabalho nos faz atentar para o fato de que a mobilidade em análise, entre mulheres investigadoras brasileiras em cursos de pós-graduação na UMinho, caracteriza-se por uma forma não hegemônica de internacionalização da educação, marcada pela necessidade de visibilidade e maior reconhecimento profissional, acrescido de um conjunto de significados subjetivos de caráter social, que as conduzem para este tipo específico de mobilidade, de modo a tentar construir novas trajetórias de atuação na ciência.

\section{REFERÊNCIAS}

Ackers, L. (2001). The participation of women researchers in the TMR Marie Curie Fellowships. Bruxelas: European Commission. ftp://ftp.cordis.europa.eu/pub/improving/docs/women_final_rpt_3march20oo. pdf

Ackers, L. (2004). Managing relationships in peripatetic careers: Scientific mobility in the European Union. Women's Studies International Forum, 27, 189-201. doi:10.1016/j.wsif.2004.03.001.

Castro, A. A. \& Neto, A. C. (2012). O ensino superior: a mobilidade estudantil como estratégia de internacionalização na América Latina. Revista Lusófona de Educação, 21, 69-96. http://revistas. ulusofona.pt/index.php/rleducacao/article/view/3082

CNPq, Conselho Nacional de Desenvolvimento Científico e Tecnológico (2015). Jovens pesquisadoras: ciência também é coisa de mulher! http://www.cnpq.br/web/guest/noticias-popularizacao/-/ journal_content/56_INSTANCE_a6MO/10157/1766926

Delicado, A. \& Alves, N. A. (2013). "Fugas de Cérebros", "Tetos de Vidro" e "Fugas na Canalização": mulheres, ciência e mobilidade. In E. Araújo; M. Fontes; S. Bento (Eds.), Para um Debate sobre Mobilidade e "Fuga de Cérebros" (pp. 8-31). Braga: Centro de Estudos de Comunicação e Sociedade, Universidade do Minho. http://www.lasics.uminho.pt/ojs/index.php/cecs_ebooks/article/ viewFile/1575/1489

França, T. \& Padilha, B. (2013). Mulheres cientistas imigrantes: entre o sexismo e racismo acadêmico. Seminário Internacional Fazendo Gênero 10 (Anais Eletrônicos), Florianópolis. ISSN 2179-510X. http:// www.fazendogenero.ufsc.br/10/resources/anais/20/1386773176_ARQUIVO_ThaisFranca.pdf

IBGE - Instituto Brasileiro de Geografia e Estatística (2015). Estatísticas de Gênero, Censo de 2010. http://www. ibge.gov.br/apps/snig/vı/?loc=0

Kaplan, R. B. (2001) English - the accidental language of science?. In U. Ammon (Ed.), The Dominance of English as a Language of Science (pp. 3-26), Berlim: De Gruyter. 
Knight, J. (2012). Cinco verdades sobre internacionalização. International Higher Education, 69. http://www. revistaensinosuperior.gr.unicamp.br/edicoes/ihe/lHE6gport.pdf

Leta, J. (2003). As mulheres na ciência brasileira: crescimento, contrastes e um perfil de sucesso. Estudos Avançados, 17 (49), 271-284. http://www.revistas.usp.br/eav/article/view/9956

Leta, J. \& Martins, F. (2008). Docentes pesquisadores na UFRJ: o capital científico de mulheres e homens. In INEP - Secretaria Especial de Políticas Públicas para as Mulheres (Ed.), Simpósio Gênero e indicadores da educação superior brasileira. Brasília: INEP.

Nogueira, M. A., Aguiar, A. M. \& Ramos, V. C. (2008) Fronteiras desafiadas: a internacionalização das experiências escolares. Revista Educação Q Sociedade, 29 (103), 355-376.

Olinto, G. (2011). A inclusão das mulheres nas carreiras de ciência e tecnologia no Brasil. Inclusão Social, 5 (1). http://revista.ibict.br/inclusao/index.php/inclusao/article/viewFile/240/208

Saboya, M. C. L. (2013). Relações de gênero, ciência e tecnologia: uma revisão da bibliografia nacional e internacional. Educação, Gestão e Sociedade, 3 (12). www.faceq.edu.br/regs.

UNESCO. (2011). Compendio mundial de la educación: comparación de las estadísticas de educación en el mundo. http://unesdoc.unesco.org/images/o019/001912/191218s.pdf.

Videira, P. (2013). A mobilidade internacional dos cientistas: construções teóricas e respostas políticas. In E. Araújo; M. Fontes; S. Bento (Eds.), Para um Debate sobre Mobilidade e "Fuga de Cérebros" (pp. 138-162), Braga: Centro de Estudos de Comunicação e Sociedade, Universidade do Minho. http://www.lasics. uminho.pt/ojs/index.php/cecs_ebooks/article/viewFile/1575/1489

Williams, C. L. (1995). Still a man's world: men who do “women's work”. Berkeley, Los Angeles: University of California Press.

Sônia Cristina S. de Azevedo Cerqueira é Professora Titular da Universidade Tiradentes (Sergipe/Brasil). Doutora em Sociologia (UFPE), atualmente realiza pesquisa pós-doutoral no Centro de Estudos de Comunicação e Sociedade (CECS), da Universidade do Minho (Braga / Portugal).

E-maiL: sonia.sociologa@gmail.com /

Universidade Tiradentes e Universidade do Minho Campus Aracaju-Centro R. Lagarto, 264. Bairro Centro, CEP: 49010-390 Aracaju/SE, Brasil

Rita Ribeiro é Professora Auxiliar do Departamento de Sociologia e investigadora do Centro de Estudos de Comunicação e Sociedade (CECS) da Universidade do Minho (Braga /Portugal).

E-mail: rmgr@ics.uminho.pt

Centro de Estudos de Comunicação e Sociedade - Universidade do Minho Campus de Gualtar, 4710-057, Braga, Portugal

* Submetido: 16-02-2015

* Aceite: 20-04-2015 